\title{
Assessment of Weight Loss Practice among Adolescents in Lower Egypt Governorates
}

\author{
${ }^{1}$ Safaa Tawific, ${ }^{2}$ Shereen Eassa, ${ }^{2}$ Lamiaa Lofty Elhawy \\ ${ }^{1}$ National Institute of Nutrition, ${ }^{2}$ Public Health and Community Medicine, Faculty Of \\ Medicine, Zagazig University'
}

\section{Abstract}

Background: Proper nutrition is essential to promote good health and wellbeing. Adolescence has been identified as an important period for establishing healthy eating behaviors. A healthy diet plan should aim for a weight-loss goal of no more than one kilogram $(\mathrm{kg})$ per week. Objective: to assess weight loss practice among adolescents and to determine association between some personal factors and weight loss practice. Method: A cross sectional study was conducted among (842) adolescent students from governmental preparatory and secondary schools in some Lower Egypt governorates (Cairo - Daqahliyah), during the academic year (2018-2019) by multistage cluster sampling technique. The students completed a structured questionnaire about weight loss practices. The anthropometric measurements (weight and height) were measured. Results: The percentage of obese and overweight students were $23.6 \%$ and $14.4 \%$ respectively. Prevalence of weight loss practice was $25.4 \%$ in all studied sample. only $11.7 \%$ of them visited nutritionist to decrease their weights. There was statistical significant relation between age and education with reducing number of meals to two or one, taking Herbs or un-prescribed medicines, Fasting and Induce vomiting where these practices were more among older age groups and Secondary educated students $(\mathrm{p}<0.001, \mathrm{p}<0.001, \mathrm{p}=0.001$ and $\mathrm{p}=0.009)$ respectively. Conclusion: Prevalence of weight loss practice was twenty five percent among studied adolescent students. Visiting dietitian was not a common weight loss practice.

Key words: Adolescences, weight loss, practices, schools, Lower Egypt

Corresponding Author: Lamiaa Lotfy El Hawy Email:lamiaa102elhawy @yahoo.com

\section{Introduction}

Proper nutrition is considered essential to promote good health and wellbeing. Maintaining a healthy diet can help in prevention and treatment of diet-related diseases, like cancer, obesity cardiovascular disease, and diabetes. ${ }^{1}$ Worldwide, the second leading risk factor for premature death is an unhealthy diet. ${ }^{2}$ Evidence suggests that maintaining weight loss is very difficult, and preventing weight gain may be important in decreasing the prevalence of obesity. ${ }^{3}$ Childhood and adolescence have been identified as a very important period for establishing healthy eating behaviors. Establishing healthy habits during Childhood like increased physical activity, reduced time spent sedentary, proper sleep, and healthy eating habits can help in prevention of obesity in adulthood and later on. ${ }^{4}$ Unhealthy eating behaviors and habits are considered risk factors for many non-communicable diseases (NCDs), such as cancer, obesity, cardiovascular diseases, and diabetes. ${ }^{5}$ It is believed that different behaviors and habits are mostly shaped during childhood and adolescence. ${ }^{6}$ This highlights the importance of this period as 
sensitive phases that provide great opportunities for healthy preventive interventions to promote their future health. ${ }^{7}$ Studies had shown that obese adolescents are likely to have at least one risk factor for cardiovascular diseases. ${ }^{8}$ Also, there has been a recent increase in the percent of adolescents with type 2 diabetes corresponding to the increase of overweight status and obesity?.

A healthy diet plan should include physical activity, and also should aim for a weightloss goal of no more than one kilogram (kg) per week. ${ }^{10}$ Weight-loss practices that promote rapid weight-loss like fasting, skipping meals, very low-calorie diets, and products or supplements that have not been researched yet, as these weight-loss methods are not effective, safe, or realistic for long-term weight-loss. ${ }^{10}$ Unhealthy weight loss practices broadly refers to the use of dieting methods that provide rapid and easy weight-loss, which are often times restrictive and difficult to be maintained. It usually focuses on a shortterm rather than long-term weight loss methods. ${ }^{11}$ The popularity of unhealthy weight loss practice is problematic because they are not often effective, and may cause adverse effect on health and not recommended by health professionals. ${ }^{12}$ The aims of the study are to assess weight loss practice either (healthy or unhealthy) among adolescents, to determine association between some personal factors and weight loss practice and to know sources of their information.

\section{Method}

This paper is part of project about nutrition among adolescent follow the National Nutrition institute. A cross sectional study was conducted among students of governmental preparatory and secondary schools in some Lower Egypt governorates (Cairo - Daqahliyah), Egypt during the academic year 2018-2019.
Inclusion criteria: Apparently healthy adolescent's students aged (11-19) years, attending governmental preparatory and secondary schools.

Exclusion criteria: private or international preparatory and secondary schools. Governmental mixed schools.

Sample size calculation: By assuming, prevalence of weight loss practice among adolescent was $(47.1 \%)^{13}$ and total population of our study are around 10 million $^{14}$ at $80 \%$ power of study and $95 \%$ confidence level the sample was (766) and with $10 \%$ non-response rate, the sample was (842). It is calculated by OpenEpi ${ }^{15}$ (Dean et al., 2013).

Sampling Technique: Multi stage cluster sampling technique was used to draw a representative sample as follows: First stage: by simple random method two governorates were randomly selected from all Lower Egypt governorates (10 governorates). They were Cairo governorate and Daqahliyah governorate. Second stage: in each governorate, by simple random method one educational district was selected from all educational districts, in Cairo, Miser aljadida educational district (from 32 educational district) and in Daqahliyah, mayit ghamar educational district (from 17 educational district) were randomly drown in each governorate. Third stage: in each district, preparatory and secondary schools were divided into two strata according to gender and from each group, one school was randomly selected. Fourth stage: according to proportion allocation, one, two or three classes were randomly selected from selected school and each class was taken as a cluster.

Total Number of adolescent students in Cairo governorate was 724470 students (468630 in preparatory phase - 255840 in secondary phase) and in Daqahliyah governorate were 421798 students (312563 in preparatory phase -109235 in secondary 
phase). Taking proportion allocation in consideration, four schools in each

Table (1): Names of Selected Schools and Numbers of Classes

\begin{tabular}{|c|c|c|c|}
\hline \multicolumn{2}{|l|}{$\begin{array}{c}\text { Cairo governorate. } \\
\text { Miser Aljadida Educational District }\end{array}$} & \multicolumn{2}{|c|}{$\begin{array}{c}\text { Daqahliyah governorate } \\
\text { Mayit Ghamar Educational District }\end{array}$} \\
\hline Name of schools & $\begin{array}{l}\text { No of } \\
\text { classes }\end{array}$ & Name of schools & $\begin{array}{l}\text { No of } \\
\text { classes }\end{array}$ \\
\hline $\begin{array}{l}\text { Hanifa Al Selehdar Preparatory School } \\
\text { For Girls }\end{array}$ & 3 & $\begin{array}{l}\text { Jihan Sadate Preparatory School For } \\
\text { Girls }\end{array}$ & 2 \\
\hline Al Tubary Preparatory School For Boys & 3 & $\begin{array}{l}\text { Al Saeid Preparatory School For } \\
\text { Boys }\end{array}$ & 2 \\
\hline $\begin{array}{l}\text { Hanifa Al Selehdar Secondary School } \\
\text { For Girls }\end{array}$ & 2 & $\begin{array}{l}\text { Al Shahid Ayman Al Desoky } \\
\text { Secondary School For Girls }\end{array}$ & one \\
\hline Al Tubary Secondary School For Boys & 2 & $\begin{array}{l}\text { Omar Ben AL Khatab Secondary } \\
\text { School For Boys }\end{array}$ & one \\
\hline
\end{tabular}

educational district was selected as shown in table (1).

Table (2): Socio-demographic data among the studied group

\begin{tabular}{|c|c|c|}
\hline \multirow[t]{2}{*}{ Socio-demographic data } & \multicolumn{2}{|c|}{$\begin{array}{l}\text { Study group } \\
\quad(n=842)\end{array}$} \\
\hline & No & $\%$ \\
\hline \multicolumn{3}{|l|}{ Age/ years } \\
\hline - Less than or equal 14 years & 425 & 50.5 \\
\hline - More than 14 years & 417 & 49.5 \\
\hline \multicolumn{3}{|l|}{ Sex } \\
\hline - Male & 410 & 48.7 \\
\hline - Female & 432 & 51.3 \\
\hline \multicolumn{3}{|l|}{ Education } \\
\hline - $\quad$ Preparatory & 577 & 68.5 \\
\hline - $\quad$ Secondary & 265 & 31.5 \\
\hline \multicolumn{3}{|l|}{ Governorate } \\
\hline - $\quad$ Cairo & 505 & 60.0 \\
\hline - Daqahliyah & 337 & 40.0 \\
\hline \multicolumn{3}{|l|}{ SES } \\
\hline - Low & 75 & 8.9 \\
\hline - $\quad$ Moderate & 356 & 42.3 \\
\hline - High & 411 & 48.8 \\
\hline
\end{tabular}

The students completed a structured questionnaire which took about (10-15 min) to be completed. No one refused to complete it. It is composed of the following sections: Section 1: Personal history which include age, sex, education, occupation, family members; economic status, home sanitation, health care to calculate socioeconomic status of the target group. ${ }^{\mathbf{1 6}}$ This scale consisted of 7 domains with score of 84 . Socioeconomic level was classified into: (1) Low socioeconomic class: less than 42 score.
(2) Moderate socioeconomic class: equal 43-63 score. (3) High socioeconomic class: more than or equal 64 score. Section 2: questions about Weight loss practices either healthy or unhealthy. Questions about Healthy practice: Reduce the amount of food (eating all types of food), Increase physical activity with eating all types of food, Calculate and reduce Calories and, or Visiting Nutrition specialist. Questions about Unhealthy practice: Reduce number of meals to two or one, Taking Herbs or un prescribed medicines, Taking only A certain type of food, Fasting and, or Induce vomiting ${ }^{17}$.Questions about the practice: like how long did you follow the $\operatorname{diet}(\mathrm{s})$ ? How many times did you follow the $\operatorname{diet}(\mathrm{s})$ ? Did you reach to your goal? Did you increase in weight after stopping the diet? Finally, Source of their information: friends, internet, TV or nutrition specialist. The Questionnaire was validated by a panel of experts in nutrition specialty and tested for reliability (0.8) .The Arabic translation was valid and reliable.

Anthropometric measurements: (weight, height, BMI). Anthropometric measurements were taken for all students. Body weight was measured for the students in light clothing with bar feet or with stockings using a digital scale to the nearest $1 \mathrm{~kg}$. The digital scale was checked daily for quality control. Also, height was measured without shoes and recorded to the nearest $1 \mathrm{~cm}$. The outcome variable 
definitions: BMI was calculated from the weight $(\mathrm{kg}) /$ height $\left(\mathrm{m}^{2}\right)$.

Table (3): weight management practice among the studied group

\begin{tabular}{|c|c|c|}
\hline \multirow{2}{*}{ Items } & \multicolumn{2}{|c|}{ Study group $(842)$} \\
\hline & No & $\%$ \\
\hline \multicolumn{3}{|l|}{ Following regimen to decrease weight } \\
\hline - Yes & 214 & 25.4 \\
\hline - $\quad$ No & 628 & 74.6 \\
\hline Weight management practice & $\mathrm{N}=214$ & $\%$ \\
\hline \multicolumn{3}{|l|}{ Healthy practice: } \\
\hline - Reduce the amount of food (eating all types of food) & 79 & 36.9 \\
\hline - Increase physical activity with eating all types of food & 49 & 22.9 \\
\hline - Calculate and reduce Calories & 2 & 0.9 \\
\hline - Visiting Nutrition specialist & 25 & 11.7 \\
\hline \multicolumn{3}{|l|}{ Unhealthy practice } \\
\hline - Reduce number of meals to two or one & 40 & 18.7 \\
\hline - Taking Herbs or un prescribed medicines & 23 & 10.7 \\
\hline - Taking only A certain type of food & 25 & 11.7 \\
\hline - Easting & 9 & 4.2 \\
\hline Induce vomiting & 6 & 2.8 \\
\hline \multicolumn{3}{|l|}{ period of following regimen } \\
\hline - $\quad<4$ weeks & 155 & 72.4 \\
\hline - $\quad \geq 4$ weeks & 59 & 27.6 \\
\hline \multicolumn{3}{|l|}{ Reach your goal after regimen } \\
\hline - Yes & 146 & 68.2 \\
\hline - $\quad$ No & 68 & 31.8 \\
\hline \multicolumn{3}{|l|}{ Weight back after stop diet } \\
\hline - $\quad$ Yes & 113 & 52.8 \\
\hline - $\quad \mathrm{No}$ & 101 & 47.2 \\
\hline \multicolumn{3}{|l|}{ Times to follow regimen } \\
\hline - Once & 133 & 62.1 \\
\hline - $\quad$ Twice & 55 & 25.7 \\
\hline - $\quad$ More than twice & 26 & 12.1 \\
\hline
\end{tabular}

Body mass index $(\mathrm{BMI})=[$ Weight $(\mathrm{kg}) /$ Height $\left.(\mathrm{m})^{2}\right]$. In this study growth charts for adolescents were used. By putting BMI against percentile curves of the standard Egyptian growth charts instructed by faculty of medicine Cairo University and National Re-search Center ${ }^{18}$, underweight: less than 5th percentile of BMI; normal weight: from 5th to or equal 85th percentile of BMI; over weight: more than 85th to less than 95th percentile of BMI and obese: more than or equal to $95^{\text {th }}$ percentile for age and sex compared to corresponding percentile.

A Pilot study was carried out on 84 adolescents $(10 \%$ of the studied adolescents who were selected randomly from the mentioned settings and were excluded from the main study sample to evaluate the clarity, applicability, reliability and to estimate time needed to fill in the questionnaire.

\section{Statistical analysis}

Data were analyzed using the Statistical Package of Social Science (SPSS) program for Windows (Standard version 20). The normality of data was first tested with onesample Kolmogorov-Smirnov test.

Qualitative data were described using number and percent. Association between categorical variables was tested using Chisquare test and Chi-square for trend while Fischer exact test was used when expected cell count less than 5 . Continuous variables 
Table (4): Relation between Socio-demographic data and different types of unhealthy weight loss practice:

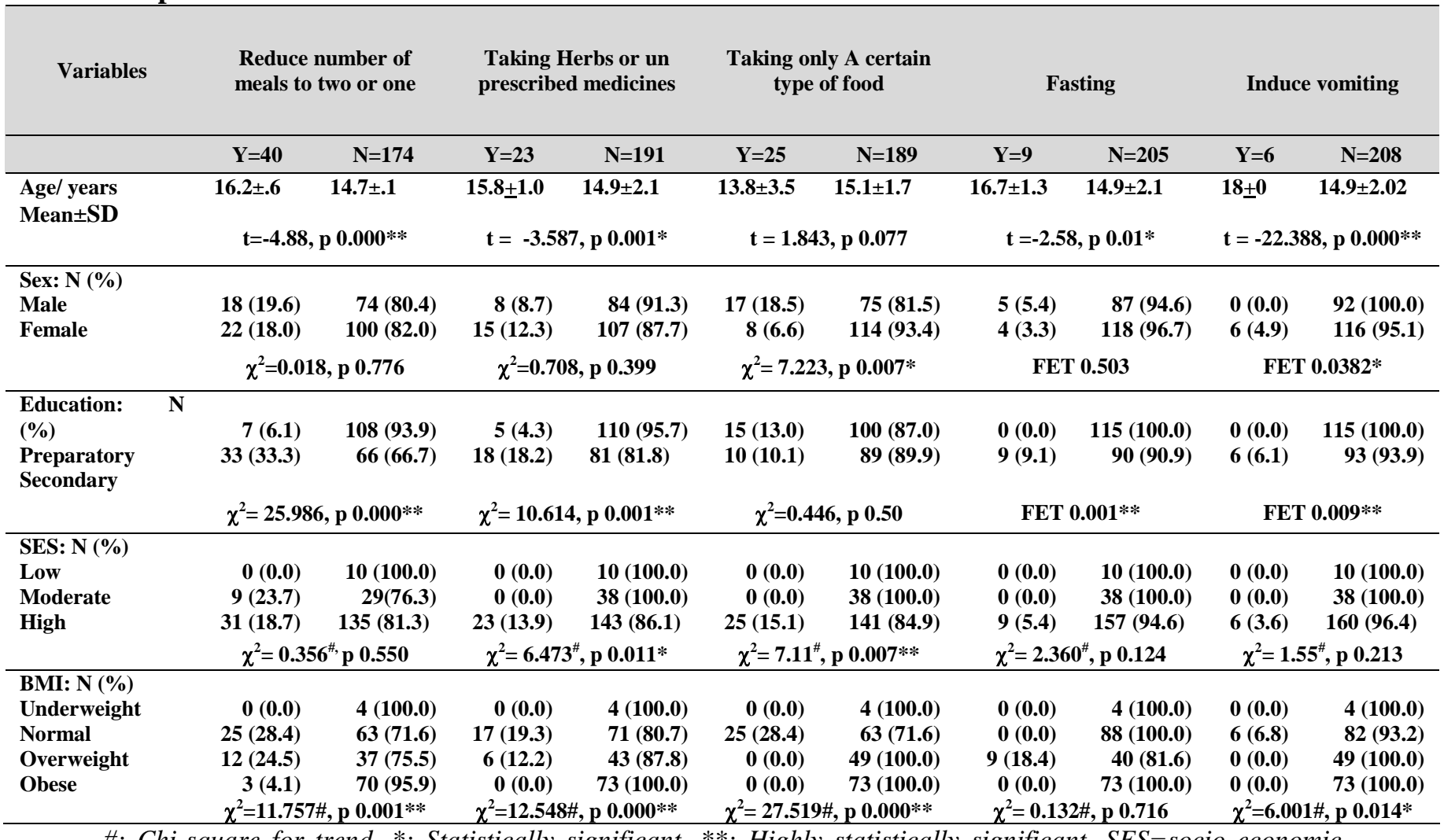

\#: Chi-square for trend, *: Statistically significant, **: Highly statistically significant, SES=socio economic standard, FET = fisher exact

were presented as mean \pm SD (standard deviation) for parametric data. The two groups were compared with Student t test. For all above mentioned statistical tests done, the threshold of significance is fixed at $5 \%$ level (p-value). The results were considered: Non-significant when the probability of error is more than 5\% ( $\mathrm{p}>$ 0.05). Significant when the probability of error is less than $5 \%(\mathrm{p} \leq 0.05)$.

The smaller the p-value obtained, the more significant are the results.

\section{Ethical Considerations}

This study was carried out within the ethics of scientific research an official permission was taken from National Nutrition institute. to all head directorates of education and directors of the studied schools in each governorate. All subjects were fully informed about the nature and objectives of the study and an oral informed consent was taken from them. All data were confidential and used only for the research purpose and they were not exposed to any harm or risk.

\section{Results}

The largest percentage of the studied students were Female (51.3\%), of high social class $(48.8 \%)$, in Preparatory phase $(68.5 \%)$ from Cairo governorate $(60.0 \%)$ and $(50.5 \%)$ of them, their ages were Less than or equal 14 years old (Table 2).

The percentage of obese and overweight students were (23.6\%-14.4\%) respectively, about $(40.0 \%)$ of adolescents were within the healthy weight per BMI percentile and $(22.3 \%)$ were under weight (Results not tabulated).

Prevalence of weight loss practice was $(25.4 \%)$ of studied sample. only $(11.7 \%)$ of studied students who tried to lose weight,

\begin{tabular}{lllll}
\hline The Egyptian Journal of Community Medicine & Vol. 38 & No. 2 & April & 2020
\end{tabular}


Table (5): Relation between Socio-demographic data and different types of healthy weight loss practice

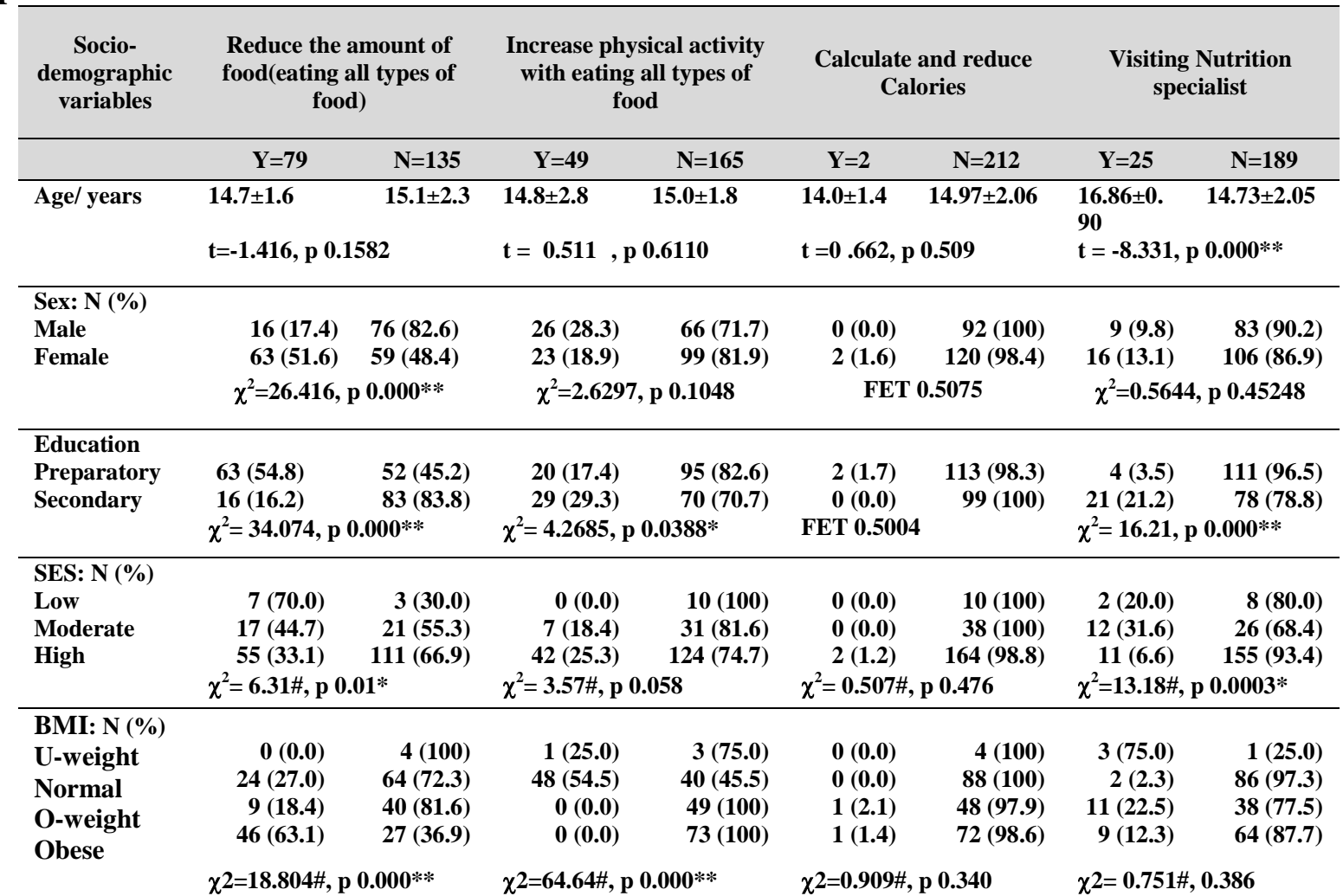

\#: Chi-square for trend, *: Statistically significant, **: Highly statistically significant, SES=socio economic standard, FET = fisher exact

visited Nutrition specialist to decrease their weights (Table 3). As regard unhealthy weight loss practices, reducing number of meals to two or one meal per day was most common $(18.7 \%)$ of all unhealthy practices. As regard healthy weight loss practice, reducing the amount of food with eating all types of food and increasing physical activity with eating all types of food were more common $(36.9 \%$ and $22.9 \%$ ) respectively (Table 3 )

The majority $(72.4 \%)$ of them doing diet less than 4 weeks, (68.2\%) reached their goal after regimen but (52.8\%) gain weight back after stop diet and most of them $(62.1 \%)$ were following their regimen for the first time (Table 3).

There was statistical significant relation between age and education with reducing number of meals to two or one, taking herbs or un prescribed medicines, fasting and induce vomiting where these practices were more among age groups (16.2 \pm 1.6 , $15.8 \pm 1.01, \quad 16.7 \pm 1.3$ and $18 \pm 0$ ) respectively and secondary educated students $(\mathrm{p}<0.001, \mathrm{p}=0.001, \mathrm{p}=0.001$ and $\mathrm{p}=0.009$ ) respectively (Table 4$)$.

There was statistically significant relation between sex and taking only a certain type of food where it was more among male students $(p=0.007)$ (Table 4)

There was statistically significant relation between socio economic standard (SES) and taking herbs or un prescribed medicines and taking only a certain type of food in which, these practices were significantly higher among high SES students $\quad(p=0.011$ and $\mathrm{p}=0.007)$ respectively (Table 4)

There was statistical significant relation between body mass index (BMI) and reducing number of meals to two or one, taking herbs or un prescribed medicines, taking only a certain type of food and 
induce vomiting in which these practices were significantly higher among normal (BMI) students( $\mathrm{p}=0.001, \mathrm{p}<0.001$, $\mathrm{p}<0.001$ and $\mathrm{p}=0.014$ ) respectively (Table 4). There was statistical significant relation between sex, education, socio economic standard (SES) and body mass index (BMI) with reducing the amount of food (eating all types of food) where this practice was higher among obese female students, preparatory educated of low social class $\quad(\mathrm{p}<0.001, \quad \mathrm{p}<0.001$, $\mathrm{p}<0.001$ and $\mathrm{p}=0.01$ ) respectively (Table $5)$.

There was statistical significant relation between education and body mass index (BMI) and increasing physical activity with eating all types of food where this practice was higher among secondary educated students, of normal (BMI) ( $\mathrm{p}=$ 0.038 and $p<0.001$ ) respectively (Table 5 ).

There was statistical significant relation between age, education and socio economic standard (SES) and visiting nutrition specialist where this practice was higher among students, their ages $(16.86 \pm 0.90)$, secondary educated of moderate social class $(\mathrm{p}<0.001, \mathrm{p}<0.001$ and $\mathrm{p}=0.0003$ ) respectively (Table 5).

Most common sources of adolescent students' information were internet and social media (43\%), TV (25\%) and their friends $(22 \%)$. But nutritionist was the least source of their information, only (10\%) (Results not tabulated).

\section{Discussion}

More than quarter of the adolescents in our sample was either overweight or obese, which is considered dangerous sing among this age group. This finding is similar to rates reported by other Egyptian studies in other governorates like study carried out among adolescent students, in Alexandria, in which $26.5 \%$ of adolescents were overweight and $13.3 \%$ are obese ${ }^{19}$ and Talat and Shahat (2016) in Sharkia governorate, also found that the prevalence of overweight and obesity was $20 \%$ and $10.7 \%$ respectively. ${ }^{20}$ Arabian countries like Saudi Arabia ${ }^{21}$, Tunis ${ }^{22}$ and Palestine ${ }^{23}$ reported that obesity among adolescents is a raising problem. Developed countries as USA; also reported prevalence of obesity among adolescents aged 12 to 19 years was $20.5 \%$ in $2011-2014 .^{24}$ and this matched with another study carried out in Florida in which A quarter of the sample $(25.1 \%)$ was either overweight or obese. ${ }^{25}$ This may be explained by un healthy life style such as unhealthy eating habits (snacks and fast food), lack of physical activity and spending more times watching TV, playing games on internet or on social media.

Prevalence of weight loss practice was (25.4\%) among studied adolescent students. This percent was less than other studies, like Attlee A. et al,( 2017) study carried out among Adults in the United Arab Emirates reported that $(55.4 \%)$ of them were trying to lose weight ${ }^{13}$ and Brittany Cormier, (2018) thesis reported that $(44.2 \%)$ of youth and young adults in Canada trying to decrease their weights. ${ }^{17}$ This may be explained by many reasons the first, different cultures among adolescent students in Egypt and adolescents from the United Arab Emirates and Canada.The second reason, may be that weight loss practice was not the first priority among Egyptian adolescent students because many students are more interesting in studying well and getting the highest marks rather than decreasing their weights.

Reducing the amount of food and increasing physical activity were common healthy weight loss practices among studied sample while reducing number of meals to one or two meal per day was common unhealthy weight loss practice. Visiting nutrition specialist was not a common weight loss practice among 
adolescent in this study. Attlee A. et al., (2017) reported that most common weight loss practices found in their study included increasing physical activity, eating less fat, and consuming fewer calories but visiting dietitian was not a common weight loss practice and ranked 9th in the order of participants' preferences. $^{13}$ Lin et al. (2013) reported exercise to be a more common method than switching to foods with lower calories for losing weight. ${ }^{26}$ Kruger et al. (2004) found that only onethird of all those people who were trying to lose weight reported eating less calories and exercising more. ${ }^{27}$ The majority of studied adolescents followed diet less than 4 weeks and reached their goal after regimen but fifty two percent gained weight back after stopping diet and sixty two percent were following their regimen for the first time.. These finding may be explained by new era of being slim beside they are interested their shape and appearance at this age group and they loss their weight rapidly because they are still in growing age which characterized by increase the metabolism. They gained their weight again because they follow the diet for a short period and they returned back to their unhealthy life style.

As regard unhealthy practices, reducing number of meals to two or one, taking herbs or UN prescribed medicines, fasting and induces vomiting where these practices were more among older age groups secondary educated students. Duan et al., (2014), study carried out in Florida, reported that Adolescents between the ages (12 - 15 years) were less likely to exhibit unhealthy weight loss practice compared to older adolescents (16 years or older). ${ }^{25}$ This may be explained by Egyptian adolescents less than 15 years old are still not interested in their weight and shape, comparing to older adolescents who became interested in being slim so they try to reach their goals even with using unhealthy practices.

Our study revealed that there was no relation between sex and different unhealthy weight loss practices except taking only a certain type of food where it was more among male students. This may be explained by male are interested in muscular shape so they increase in taking diet rich in protein. Other studied showed that females were more likely than males to exhibit unhealthy weight loss practices. $^{28-29}$ Duan et al., (2014), also reported that females were more likely to engage in at least one unhealthy weight loss practice compared to male. ${ }^{25}$ Our study also revealed that students of high social class were more to practice unhealthy weight loss practices like taking herbs or UN prescribed medicines and taking only a certain type of food .This may be explained by increasing financial ability to try new methods of weight loss.

The current study revealed that students of normal body mass index were more to practice unhealthy weight loss practices like reducing number of meals to two or one, taking herbs or UN prescribed medicines, taking only a certain type of food and induces vomiting. But Duan et al., (2014), study carried out in Florida, reported that overweight and obese adolescents were significantly more likely than their healthy weight counterparts to exhibit at least one unhealthy weight loss practice. ${ }^{25}$ This may be explained by they did these practices before or in the past and now they are of normal (BMI).

Most common sources of adolescent students' information, in this study, were internet and social media, TV and their friends. But nutritionist was the least source of their information. Similar studies showed the same finding, Brittany Cormier, (2018) revealed that the two most common sources of information were the internet and social media ${ }^{17}$ and Attlee A. et 
al.,( 2017) reported that most common source of information was from friends and Internet. ${ }^{13}$ This may explain the reasons why the participants follow unhealthy weight loss practices, as their information from internet or from their friends may be distorted and incorrect.

\section{Conclusion}

More than quarter of the adolescents in our sample was either overweight or obese. Prevalence of weight loss practice was twenty five percent among studied adolescent students. Visiting dietitian was not a common weight loss practice. Internet and social media were most common sources of adolescent students' information.

\section{Recommendations}

Application of further study among adolescent students in private or international schools. Increasing awareness of students by health education sessions about hazards of obesity, types of healthy weight loss practices and importance of visiting nutrition specialist to get correct information about different types of healthy weight loss practices which suitable for them.

\section{Limitations of the study:}

first: this study was carried out in governmental schools not in private or international schools due to the difficulty in getting the approval to enter theses schools. Second: questionnaire did not contain all different weight loss practices, we asked about common ones because it would need more time if filling the questionnaire

\section{Acknowledgment}

Great thanks to every person participate in completing this work; all educational directorates, students, their teachers in all studied schools in each governorate and all members from National Nutrition institute who provided us with all instruments we needed.
Conflicts of Interest The authors report no conflicts of interest

\section{References}

1. Public Health Agency of Canada: Healthy living can prevent disease [Internet]. 2011 [cited 2017 Dec 18]. Available from: https://www.canada.ca/en/public-

health/services/chronicdiseases/healthy-livingprevent-disease.html .

2. Global Burden of Disease Study: Global, regional, and national comparative risk assessment of 84 behavioural, environmental and occupational, and metabolic risks or clusters of risks, 1990-2016: A systematic analysis for the Global Burden of Disease Study 2016. Lancet [Internet]. 2017 Sep 16 [cited 2017 Dec 5];390(10100):1345-422. Available

from:

http://www.ncbi.nlm.nih.gov/pubmed /28919119.

3. Pandita A, Sharma D, Pandita D, Pawar S, Tariq M, Kaul A: Childhood obesity: Prevention is better than cure. Diabetes Metab Syndr Obes [Internet]. 2016 [cited 2017 Oct 25];15(9):83-9. Available from: http://www.ncbi.nlm.nih.gov/pubmed/2704213 3. Wilkinson D, Mccargar L.: Prevention of overweight and obesity in young Canadian children [Internet]. 2008 [cited 2017 Nov 28].

4. Ezzati M, Riboli E.:Behavioral and dietary risk factors for noncommunicable diseases. $\mathrm{N}$ Engl J Med. 2013;369(10):954964. doi:10.1056/NEJMra1203528.

5. Resnick MD, Catalano RF, Sawyer SM, Viner R, Patton GC: Seizing the opportunities of adolescent health. Lancet. 2012;379(9826):1564-1567. doi:10.1016/S0140-6736(12)604723.

6. Sawyer SM, Afifi RA, Bearinger LH, et al. Adolescence. A foundation for future health 2012;379(9826):1630-1640.

7. Freedman DS, Dietz WH, Srinivasan SR, Berenson GS. Risk factors and adult body mass index among overweight children the Bogalusa Heart Study. Pediatrics 2009; 123: 750-757.

8. Centers for Disease Control and Prevention (CDC). Overweight and Obesity. Basics about Childhood Obesity2012. 
9. Dietitians of Canada. Guidelines for choosing a weight loss program 2015, Available from:

https://www.dietitians.ca/Your-

Health/Nutrition-A Z/Weight-Concerns/ Guidelines-for-Choosing-a-Weight-Loss-

Program.aspx (cited 2018 Jan 11).

10. World Health Organization. Healthy diet. 2015, Available from: http://www.who.int/ mediacentre/factsheets/fs394/en/.(cited 2017 Dec 15)

11. Dietitians of Canada. Get the facts on fad diets .2017, Available from: http://www.unlockfood.ca/en/Articles/Weight-

Loss/Get-the-Facts-onFad-Diets.aspx. (cited 2018 Apr 3).

12. Attlee A., Atmani N., Stromtsov V.,et al .Assessment of Weight Management Practices among Adults in the United Arab Emirates, Hindawi Journal of Nutrition and Metabolism Volume 2017, Article ID 1050749, 9 pages https://doi.org/10.1155/2017/1050749.

13. Central Agency for Public Mobilization and Statistics CAPMAS (2015).

14. Dean A., Sullivan K. and Soe M. Open Source Epidemiologic Statistics for Public Health, Version. Available from: www.OpenEpi.com, updated 2013/04/06, accessed 2018/12/12.

15. El-Gilany A, El-Wehady A, El-Wasify M. Updating and validation of the socioeconomic status scale for health research in Egypt. Eastern Mediterranean health journal2012, Vol. 18, p. 962-8. Available at: http: //www.ncbi.nlm.nih.gov/pubmed/23057390.

16. Brittany Cormier. Exposure to fad diet advertising among youth and young adults in Canada 2018, Available from: http://hdl.handle.net/10012/13846.

17. Gali I, Salah N, Hussien F, Erfan M, ElRuby M. Mazen I. et al. Egyptian growth curves 2002 for infants, children and adolescents. A. Sartorio, J.M.H. Buckler, N. Marazzi (Eds.), Crescere nel mondo, Ferring Publisher 2008.

18. Amel E Mohammed, Mona H Ibrahim, Sohair A Hagag and Hala M Mohamed: Obesity and Self-Esteem among School Adolescent Students, Alexandria City, Egypt. The Egyptian Journal of Community Medicine. 2019, Vol. 37 .No. 3 (16-24).
19. Talat M, Shahat E. Prevalence of overweight and obesity among preparatory school adolescents in Urban Sharkia Governorate, Egypt. Egyptian Pediatric Association Gazette, 2016;64(1): 20-25. Available at: https://www.sciencedirect.com /science/article/pii/S1110663815000610 https://doi.org/10.1016/j.epag.2015.11.004. 20. Alqarni S M. A Review of Prevalence of Obesity in Saudi Arabia. J Obes Eat Disord. 2016; 2(2):25. doi: 10.21767/24718203. 100025 Available from: http:// obesity. imedpub.com/a-review-of-prevalenceofobesity-in-saudi-arabia.php?aid=17699.

21. Boukthir S, Essaddam L, Mazigh Mrad S, Ben Hassine L, Gannouni S, Nessib F. et al. Prevalence and risk factors of overweight and obesity in elementary schoolchildren in the metropolitan region of Tunis, Tunisia. Tunis Med. 2011; 89(1): 50-4.

22. Abdeen Z, Jildeh C, Dkeideek S, Qasrawi R, Ghannam I, Al Sabbah H. "Overweight and Obesity among Palestinian Adults: Analyses of the Anthropometric Data from the First National Health and Nutrition Survey .Journal of Obesity 2012, Article ID 213547, 12 pages. 23. Ogden C L, Carroll M D, Lawman H G, Fryar C D, Kruszon-Moran D, Kit B K, et al. Trends in obesity prevalence among children and adolescents in the United States, 19881994 through 2013-2014. JAMA, 2016; 315(21):2292-9.

24. Duan R, Vidot DC, Hlaing WM. Weight Loss Practice by Weight Status among Adolescents. Austin J Public Health Epidemiol. 2014; 1(1): 1003.

25. Lin C.-T. J., Gao,Z. and Lee J.-Y., "Associations between self-reported weight management methods with diet quality as measured by the Healthy Eating Index-2005," Preventive Medicine,vol.57,no.3,pp.238243,2013.

26. Kruger J., Galuska, D. A. . Serdula, M. K and Jones, D. A "Attempting to lose weight: Specific practices among U.S. Adults," The American Journal of Preventive Medicine, 2004 vol. 26, no.5,pp.402-406,.

27. Lampard AM, Maclehose RF, Eisenberg ME, Neumark-Sztainer D, Davison KK. Weight-Related Teasing in the School Environment: Associations with Psychosocial 
Health and Weight Control Practices among Adolescent Boys and Girls. 2014 .

28. Gonsalves D, Hawk H, Goodenow C. Unhealthy Weight Control Behaviors and
Related Risk Factors in Massachusetts Middle and High School Students. Matern Child Health J. 2013. 